\title{
Cytotoxicity and effect on protease activity of copolymer extracts containing catechin
}

\section{Zarella, Bruno Lara}

2016-05-01

Zarella , B L , Rabelo Buzalaf , M A , Kato , M T, Hannas , A R , Salo , T, Tjaderhane , L \&

Prakki , A 2016 , ' Cytotoxicity and effect on protease activity of copolymer extracts

containing catechin ' , Archives of Oral Biology , vol. 65 , pp. 66-71 . https://doi.org/10.1016/j.archoralbio.2016.01.01

http://hdl.handle.net/10138/223927

https://doi.org/10.1016/j.archoralbio.2016.01.017

publishedVersion

Downloaded from Helda, University of Helsinki institutional repository.

This is an electronic reprint of the original article.

This reprint may differ from the original in pagination and typographic detail.

Please cite the original version. 


\title{
Cytotoxicity and effect on protease activity of copolymer extracts containing catechin
}

\author{
Bruno Lara Zarella ${ }^{\mathrm{a}}$, Marília Afonso Rabelo Buzalaf ${ }^{\mathrm{a}, *}$, Melissa Thiemi Kato ${ }^{\mathrm{b}}$, \\ Angelica Reis Hannas ${ }^{\mathrm{a}}$, Tuula Salo ${ }^{\mathrm{c}, \mathrm{d}}$, Leo Tjäderhane ${ }^{\mathrm{c}, \mathrm{d}}$, Anuradha Prakki ${ }^{\mathrm{e}, * *}$ \\ a Department of Biological Sciences, Bauru School of Dentistry, University of São Paulo, Bauru, SP 17012-901, Brazil \\ ${ }^{\mathrm{b}}$ Department of Dentistry, University of Sagrado Coração, Bauru, SP 17011-160, Brazil \\ ' Institute of Dentistry, University of Oulu, and Medical Research Center Oulu, Oulu University Hospital and University of Oulu, Oulu FI-90014, Finland \\ d Department of Oral and Maxillofacial Diseases, University of Helsinki, and Helsinki University Hospital, Helsinki FI-00014, Finland \\ e Department of Clinical Sciences-Restorative, Faculty of Dentistry, University of Toronto, Toronto, ON M5G1G6, Canada
}

\section{A R T I C L E I N F O}

\section{Article history:}

Received 29 July 2015

Received in revised form 5 November 2015

Accepted 27 January 2016

\section{Keywords:}

Caries

Zymography

Matrix-metalloproteinases

Dentin

Odontoblasts

Resins

\begin{abstract}
A B S T R A C T
Objective: To evaluate cytotoxicity and effect on protease activity of epigallocatechin-gallate extracted from experimental restorative dental copolymers in comparison to the control compound chlorhexidine. Methods: Copolymer disks were prepared from bis-GMA/TEGDMA (70/30 mol\%) containing no compound (control) or $1 \% \mathrm{w} / \mathrm{w}$ of either epigallocatechin-gallate or chlorhexidine. MDPC-23 odontoblast-like cells were seeded with the copolymer extracts leached out into deionized water. Cell metabolic activity was quantified by 3-(4,5-dimethylthiazol-2-yl)-2,5-diphenyltetrazolium bromide (MTT) assay at $24,48,72 \mathrm{~h}$. Inhibition of protease activity by resin extracts was measured by a collagenolytic/ genatinolytic enzyme activity assay and gelatin zymography. Data for MTT and protease inhibition were analyzed using two-way ANOVA followed by Tukey or Bonferroni post hoc tests $(\alpha=0.05)$.

Results: The MTT revealed that at $72 \mathrm{~h}$, extracts from control (16.7\%) and chlorhexidine (22.3\%) copolymers induced significant reduction in cell metabolism $(p<0.05)$. All copolymer extracts caused enzymatic inhibition in a dose dependent manner $(p<0.01)$. Even when highly diluted, epigallocatechingallate extract had a significant antiproteolytic activity $(p<0.05)$. Zymograms showed that all extracts reduced activity of MMP-2 and MMP-9 (pro- and active forms), with MMP-9 exhibiting the highest percentage inhibition revealed by densitometry.

Conclusions: Epigallocatechin-gallate and chlorhexidine extracts did not exert cytotoxicity on evaluated cells when compared to control extracts. Both compounds retained antiproteolytic activity after extraction from a dental copolymer.

Clinical significance: Once extracted from a dental copolymer, epigallocatechin-gallate is not cytotoxic and retains antiproteolytic activity. These results may allow incorporation of epigallocatechin-gallate as a natural-safe alternative to chlorhexidine in functionalized restorative materials.
\end{abstract}

(c) 2016 Elsevier Ltd. All rights reserved.

\section{Introduction}

Resin composites are used in a variety of applications in dentistry including restorations, liners, cores, cementation, and endodontic sealers. The composition of resins has evolved

\footnotetext{
* Corresponding author at: Al. Octávio Pinheiro Brisolla, 9-75; Bauru, SP 17012901, Brazil.

** Corresponding author at: Room 352C, 124 Edward St., Toronto, ON M5G1G6, Canada.

E-mail addresses: brunolzarella@usp.br (B.L. Zarella), mbuzalaf@fob.usp.br (M.A.R. Buzalaf), thiemikato@gmail.com (M.T. Kato), angelhannas@hotmail.com (A.R. Hannas), tuula.salo@oulu.fi (T. Salo), leo.tjaderhane@oulu.fi (L. Tjäderhane), anuradha.prakki@dentistry.utoronto.ca (A. Prakki).
}

significantly since they were introduced, first aiming to improve wear resistance and polish, lower the polymerization shrinkage and later to develop self-adhesive materials (Chen, 2010). However, secondary caries (Rasines Alcaraz et al., 2014) and loss of bond strength due to proteolytic activity of collagenolytic and gelatinolytic enzymes in the hybrid layer (Tjäderhane et al., 2013), still remain to be the problems reducing the composite filling longevity. Enzymes such as MMP-2 and MMP-9, localized in dentin or saliva, may have a fundamental role in dentin organic matrix degradation and caries progression (Tjaderhane et al., 1998; Mazzoni et al., 2007). Both MMP-2 and MMP-9 were indeed found to be among the most abundant proteases found in cariesaffected dentin (Vidal et al., 2014). Future developments should 
thus aim to produce functionalized materials, with therapeutic activities, such as antibacterial and/or antiproteolytic properties (Tjäderhane et al., 2013; Jandt \& Sigusch, 2009; Delaviz, Finer, \& Santerre, 2014).

Chlorhexidine is capable of arresting caries when applied to dentin (Van Rijkom, Truin, \& vant Hof, 1996). Chlorhexidine also inhibits dentin endogenous proteases such as MMPs and cysteine cathepsins (Tjäderhane et al., 2013). This antiproteolytic effect prevents hybrid layer degradation and increases dentin bond strength durability (Tjäderhane et al., 2013), and may also participate in the prevention of dentinal caries progression (Garcia et al., 2009). The release of chlorhexidine from resins by Fickian diffusion has been widely tested in terms of mechanical and biological properties (Leung et al., 2005; Anusavice, Zhang, \& Shen, 2006; Pallan, Furtado Araujo, Cilli, \& Prakki, 2012), confirming the antibacterial efficacy also when incorporated into adhesive resin (Hiraishi, Yiu, King, Tay, \& Pashley, 2008). However, certain drawbacks of this compound such as its synthetic nature and a possible cytotoxicity to dentin odontoblastic cells (Lessa, Nogueira, Huck, Hebling, \& Costa, 2010; de Souza, de Aquino, de Souza, Hebling, \& Costa, 2007) motivate researchers to investigate alternatives.

Epigallocatechin-gallate (EGCg), a natural polyphenol from green tea, has been shown to be effective antimicrobial against Streptococcus mutans and in inhibiting acid production in dental biofilm (Hirasawa, Takada, \& Otake, 2006; Xu, Zhou, \& Wu, 2012). Incorporation of EGCg has also been shown not to adversely affect the mechanical properties of different copolymer compositions (Pallan et al., 2012), and EGCg released from these copolymers retains antibacterial activity against S. mutans (Mankovskaia, Levesque, \& Prakki, 2013). Moreover, it has been reported that EGCg inhibits dentinal proteases (Kato et al., 2012), thus preserving the long-term dentin bond strength with an effect equal to chlorhexidine (Santiago, Osorio, Neri, Carvalho, \& Toledano, 2013). However, the protease activity of compounds released from dental copolymers has not yet been demonstrated. It was therefore the objective of this study to investigate the cytotoxicity and proteaseinhibiting activities of EGCg, released by an experimental dental copolymer, and compare that to chlorhexidine. The working null hypotheses were (1) extracts from EGCg and chlorhexidine incorporated copolymers will not exert cytotoxicity against MDPC-23 odontoblast-like cells, and (2) extracts from EGCg and chlorhexidine incorporated copolymers will not exhibit collagenolytic and gelatinolytic activities.

\section{Materials and methods}

Chemicals were obtained from Sigma-Aldrich (St. Louis, MO, USA) unless otherwise specified.

\subsection{Formulation of copolymers and compound extraction}

Experimental copolymer disks ( $7 \mathrm{~mm}$ diameter $\times 2 \mathrm{~mm}$ high) were prepared from bis-GMA (bisphenol glycidyl dimethacrylate) and TEGDMA (triethyleneglycol dimethacrylate) at 70/30 mol\% ratio, containing no compound (control) or with $1 \% \mathrm{w} / \mathrm{w}$ of either epigallocatechin-gallate or chlorhexidine diacetate. The $1 \%$ compound ratio was chosen based on previous study that reported stability in mechanical properties of same copolymer incorporated with $1 \%$ of either epigallocatechin-gallate or chlorhexidine diacetate (Pallan et al., 2012). Resins were activated for visible light polymerization (Demi LED, Kerr Co., Middleton, USA; $540 \mathrm{~mW} / \mathrm{cm}^{2}$ ) by the addition of camphorquinone and 2-(dimethylamino) ethyl methacrylate (0.2\% w/w each) (Pallan et al., 2012), and stored at $6{ }^{\circ} \mathrm{C}$ until use.
A UV-vis spectrophotometer (Synergy HT Multi-Mode Microplate Reader, BioTEK, Winooski, VT, USA) was used to analyze the compound release rates $(n=3)$ after $24 \mathrm{~h}$ storage in $1 \mathrm{~mL}$ deionized water (EGCg $\mathrm{OD}_{297}$ and chlorhexidine $\mathrm{OD}_{257}$ ) at $37^{\circ} \mathrm{C}$. For the following tests, the copolymer extracts were concentrated $10 \times$ in volume (Eppendorf Concentrator Plus, Eppendorf AG, Hamburg, Germany).

\subsection{MDPC-23 odontoblast-like cell culture}

The immortalized mouse dental papilla MDPC-23 cells were maintained in Dulbecco's Modified Eagle's medium (DMEM; with high glucose, L-glutamine and sodium pyruvate) supplemented with $10 \%$ fetal bovine serum (Gibco, Grand Island, NY, USA), with $100 \mathrm{IU} / \mathrm{mL}$ penicillin, $100 \mu \mathrm{g} / \mathrm{mL}$ streptomycin and $0.25 \mu \mathrm{g} / \mathrm{mL}$ fungizone (Gibco). The cells were sub-cultured every 3 days and allowed to grow in a humidified incubator at $37^{\circ} \mathrm{C}$ with $5 \% \mathrm{CO}_{2}$ (Isotemp; Fisher Scientific, Pittsburgh, PA, USA). Studies have shown that MDPC-23 synthesizes dentin-specific proteins (i.e., dentin sialoprotein) that are synthesized mainly by odontoblasts. These findings support the idea that MDPC-23 may serve as a valuable in vitro model for studies of functional roles of odontoblasts (Shin, Yeon, Oh, \& Kim, 2006).

\subsection{MTT cytotoxicity assay}

MDPC-23 cells were seeded in DMEM in 96-well plate at $3 \times 103$ cell/200 $\mu \mathrm{L} /$ well and allowed to grow for $72 \mathrm{~h}$. At day 3 , the new medium was incorporated with the copolymer extracts diluted at $40 \mu \mathrm{L} / 100 \mu \mathrm{L}$. The cells were continuously cultured and evaluated at 24,48 and $72 \mathrm{~h}$ cell growth time points $(n=3)$. The extract from control copolymer was used as positive control and PBS (Phosphate Buffered Saline) as negative control. Cells metabolic activity was evaluated by the MTT (3-(4,5-dimethylthiazol-2-yl)-2,5-diphenyltetrazolium bromide) assay (Roche Applied Science, Indianapolis, IN, USA) as previously described (Aranha, Giro, Hebling, Lessa, \& Costa, 2010). Data were analyzed by two-way ANOVA and Tukey's post hoc test $(\alpha=0.05)$.

\subsection{Gelatinolytic/collagenolytic activity assay}

The effect of copolymer extracts on functional enzyme activity was assayed using EnzChek gelatinolytic/collagenolytic assay kit (Molecular Probes; Eugene, OR, USA) supplemented with type IV Clostridium histolyticum collagenase (Molecular Probes). The fluorescence of the collagen substrate is internally quenched and is only released when it is cleaved enzymatically into highly fluorescent, low molecular weight peptides. Different dilutions of copolymer extracts $(80 \mu \mathrm{L}$ to $1 \mu \mathrm{L})$ were mixed with quenched fluorescent substrates in a final volume of $200 \mu \mathrm{L}$ of reaction buffer in 96 -well plates $(n=6)$. The rate of proteolysis was determined by a Synergy ${ }^{\mathrm{TM}}$ Mx Monochromator-Based Multi-Mode Fluorometer (BioTek), operated at an absorption maxima of $495 \mathrm{~nm}$ and fluorescent emission maxima of $515 \mathrm{~nm}$. The assay included a series of control collagenase standards as well as reagent blanks. The change in enzymatic activity by EGCg or chlorhexidine extracts was calculated (\%) in comparison to the control extracts within each tested dilution. Data were analyzed by two-way ANOVA and Bonferroni's post hoc test $(\alpha=0.05)$.

\subsection{Zymographic analysis}

MMP-2 and MMP-9 were in-house gelatin-Sepharose columnpurified from conditioned cell culture media as previously described (Mäkelä, Salo, Uitto, \& Larjava, 1994). Aliquots of purified human MMP-2 (9 $\mu \mathrm{L}+3 \mu \mathrm{L}$ deionized water) or MMP-9 $(12 \mu \mathrm{L})$ 
Table 1

Cytotoxicity $\left(\mathrm{OD}_{570}\right)$ of experimental resin extracts towards MDPC-23 odontoblastlike cells. The lower values indicate reduction in cell viability.

\begin{tabular}{llll}
\hline Groups & \multicolumn{3}{l}{ Time point } \\
\cline { 2 - 4 } & $24 \mathrm{~h}($ s.d. $)$ & $48 \mathrm{~h}($ s.d. $)$ & $72 \mathrm{~h}($ s.d. $)$ \\
\hline No resin extract (PBS) & $1.7(0.20)^{\mathrm{Aa}}$ & $2.2(0.10)^{\mathrm{Ba}}$ & $1.8(0.10)^{\mathrm{Aa}}$ \\
Control resin extract & $1.8(0.07)^{\mathrm{Aa}}$ & $2.1(0.13)^{\mathrm{Ba}}$ & $1.5(0.11)^{\mathrm{Cb}}$ \\
EGCg resin extract & $1.8(0.08)^{\mathrm{Aa}}$ & $2.1(0.17)^{\mathrm{Ba}}$ & $1.5(0.24)^{\mathrm{Aa}, \mathrm{b}}$ \\
Chlorhexidine resin extract & $1.6(0.14)^{\mathrm{Aa}}$ & $2.0(0.11)^{\mathrm{Ba}}$ & $1.4(0.17)^{\mathrm{Ab}}$ \\
\hline
\end{tabular}

Two-way ANOVA and Tukey, $n=3, \mathrm{OD}_{570}=$ optical density at $570 \mathrm{~nm}$, s.d.: standard deviation, $\alpha=0.05$. PBS: phosphate buffered saline. Same upper-case letters indicate no statistical difference within each row. Same lower-case letters indicate no statistical difference within each column.

were incubated with $3 \mu \mathrm{L}$ of the different copolymer extracts for $2 \mathrm{~h}$ at $37^{\circ} \mathrm{C}$, and diluted into $4 \mu \mathrm{L}$ of Laemmli sample buffer. These were subjected to electrophoresis under non-reducing conditions in $10 \%$ sodium sulphate-polyacrylamide gel (SDS-PAGE) containing $1 \%$ type I bovine soluble skin gelatin. Pre-stained SDS-PAGE standards (BIO-RAD Laboratories Ltd., Hercules, CA, USA) were used as low-range molecular-weight markers. After electrophoresis $(120 \mathrm{~V} / 25 \mathrm{~A})$, the gels were incubated for $30 \mathrm{~min}$ in buffer I (50 mmol/L Tris- $\mathrm{HCl}, 2.5 \%$ Tween $80,0.02 \% \mathrm{NaN}_{3}\left(\mathrm{w} / \mathrm{v}\right.$ ) at $22^{\circ} \mathrm{C} \mathrm{pH}$ 7.5). Subsequently, the gels were incubated again for $30 \mathrm{~min}$ in buffer II $\left(50 \mathrm{mmol} / \mathrm{L}\right.$ Tris- $\mathrm{HCl}, 2.5 \%$ Tween $80,0.02 \% \mathrm{NaN}_{3}(\mathrm{w} / \mathrm{v})$, $1 \mu \mathrm{M} \mathrm{ZnCl}$, and $5 \mathrm{mmol} / \mathrm{L} \mathrm{CaCl}_{2}$ at $22^{\circ} \mathrm{C}$ ). Afterwards, the gels were incubated for $12 \mathrm{~h}$ in buffer III $(50 \mathrm{mmol} / \mathrm{L}$ Tris $\mathrm{HCl}, 5 \mathrm{mmol} / \mathrm{L}$ $\mathrm{CaCl}_{2}, 1 \mu \mathrm{M} \mathrm{ZnCl}$, and $0.02 \% \mathrm{NaN}_{3}(\mathrm{w} / \mathrm{v})$ at $\left.37^{\circ} \mathrm{C}\right)$. Gels were stained in $0.1 \%$ Coomassie Brilliant Blue R-250 for 60 min at $22^{\circ} \mathrm{C}$ and destained in a solution containing $10 \%$ acetic acid and $10 \%$ methanol for $30 \mathrm{~min}$. The gels were then scanned (Imagescanner, Amersham Biosciences, Uppsala, Sweden) and band intensities quantified with Kodak molecular imaging software (version 4.5; Kodak, Rochester, NJ, USA). The inhibition of MMP activities by EGCg or chlorhexidine copolymer extracts was calculated (\%) in comparison to the control extracts within each gel $(n=3)$.

\section{Results}

The mean compound release rates were $0.94 \pm 0.008 \mu \mathrm{g} / \mathrm{cm}^{2}$ for EGCg and $2.18 \pm 0.191 \mu \mathrm{g} / \mathrm{cm}^{2}$ for chlorhexidine. Cytotoxicity data are shown in Table 1 . The MTT assay revealed that at $24 \mathrm{~h}$ $(p=0.07)$ or $48 \mathrm{~h}(p=0.37)$ cell growth, test groups did not differ statistically from each other or from the negative control (PBS). At $72 \mathrm{~h}$, control and chlorhexidine copolymer extracts significantly reduced cell metabolism $(p<0.05)$ as compared to PBS $(16.7 \%$ and $22.3 \%$, respectively). EGCg extract did not significantly differ from any other group.

Data for gelatinase/collagenase activity are shown in Table 2 . Both EGCg and chlorhexidine extracts inhibited type IV $C$. histolyticum collagenase in a dose-dependent manner $(p<0.0001)$. When compared to the control, the chlorhexidine extract significantly inhibited enzymatic activity in all tested dilutions, except for the lowest dilution of $1 \mu \mathrm{L} / 200 \mu \mathrm{L}$ reaction buffer. All EGCg extract dilutions significantly inhibited enzymatic activity when compared to the control $(p<0.05)$.

The zymographic assays revealed four major bands. Two bands with approximate molecular mass of $72 \mathrm{kDa}$ and $66 \mathrm{kDa}$ correspond to pro-MMP-2 and MMP-2 active forms, respectively. Two other bands with approximate molecular mass of $95 \mathrm{kDa}$ and $80 \mathrm{kDa}$ correspond to pro-MMP-9 and MMP-9 active forms, respectively. These bands were confirmed to be MMPs as their activities were completely inhibited by 1,10-phenanthroline, a specific MMP inhibitor (data not shown). All copolymer extracts in the increasing percentage order of control, EGCg and chlorhexidine, reduced gelatinolytic activities of pro- and active MMP-2 and MMP-9, with the latter exhibiting higher percentage inhibition as revealed by densitometry (Figs. $1 \mathrm{a}$ and $1 \mathrm{~b}$ ).

\section{Discussion}

When testing different copolymer extracts towards MDPC23 cells, our results were in line with Yasuda et al. (Yasuda et al., 2008) who reported cytotoxicity caused by polymerized resinous agents to be time dependent and detectable at $72 \mathrm{~h}$ cell growth. At $72 \mathrm{~h}$, extracts from control copolymer induced significant reduction of $16.7 \%$ in cell metabolism. Leachable components of copolymers include unreacted monomers, oligomers and free radical species that are associated with several forms of tissue damage (Kunawarote et al., 2010). Also at $72 \mathrm{~h}$, chlorhexidine copolymer extract led to cell metabolism reduction of $22.3 \%$. The dissociation of chlorhexidine salts in positively charged ions may have caused additional release of low molecular weight components from the cell wall, as these ions adsorb to the cell wall causing alterations in the osmotic balance (Lessa et al., 2010).

The fact that the cytotoxicity of EGCg extract did not statistically differ from any other group suggests that the observed reduced cell metabolism ( $16.7 \%$, similar to positive controls) was mainly caused by the copolymer by-products. Nonetheless, the lower EGCg release rates than for chlorhexidine should be taken into consideration. Although EGCg $(\sim 5 \mathrm{mg} / \mathrm{ml}, \mathrm{pH} 7)$ is more soluble in water than chlorhexidine ( $\sim 3.5 \mathrm{mg} / \mathrm{ml}, \mathrm{pH} 7)$, diffusion of EGCg through copolymer chains is probably prevented by its more branched polyphenolic molecular structure and by a possible hydrogen bonding through bis-GMA pendant hydroxyl groups (Pallan et al., 2012). Catechins have also been recognized to have excellent chemopreventive properties, including protection of normal cells against genotoxic effects (Roy, Chakrabarty, Sinha, Bhattacharky, \& Siddiqi, 2003). Antioxidants like EGCg are capable of neutralizing free radical species, as reactive oxygen can abstract hydrogen atoms from EGCg (Kunawarote et al., 2010). However, the in vitro cytotoxicity findings do not directly infer in vivo conditions. Many factors contribute in decreasing the cytotoxic effects of dental material leachable components in vital teeth, such as diffusion barrier and intermolecular interactions with dentin tissue, positive intrapulpal pressure, and the presence of outward

Table 2

Inhibition of proteolytic activity as observed with the EnzChek gelatinase/collagenase assay. The values, expressed in U/mL, demonstrated the enzyme activity.

\begin{tabular}{|c|c|c|c|}
\hline $\begin{array}{l}\text { Solution subfractions } \\
(\mu \mathrm{L} / 200 \mu \mathrm{L})\end{array}$ & Control resin extract (s.d.) & EGCg resin extract (s.d.) & Chlorhexidine resin extract (s.d.) \\
\hline 1 & $0.197(0.008)^{\mathrm{Aa}}$ & $0.151(0.012)^{\mathrm{Ba}}$ & $0.178(0.012)^{\mathrm{Aa}}$ \\
\hline 5 & $0.192(0.005)^{\mathrm{Aa}}$ & $0.143(0.008)^{\mathrm{Ba}}$ & $0.153(0.015)^{\mathrm{Bb}}$ \\
\hline 10 & $0.182(0.006)^{\mathrm{Aa}}$ & $0.113(0.041)^{\mathrm{Ba}}$ & $0.130(0.013)^{\mathrm{Bb}}$ \\
\hline 40 & $0.129(0.037)^{\mathrm{Ab}}$ & $0.103(0.011)^{\mathrm{Bb}}$ & $0^{\mathrm{Cc}}$ \\
\hline 80 & $0.103(0.011)^{\mathrm{Ac}}$ & $0.036(0.040)^{\mathrm{Bc}}$ & $0^{\mathrm{Cc}}$ \\
\hline
\end{tabular}

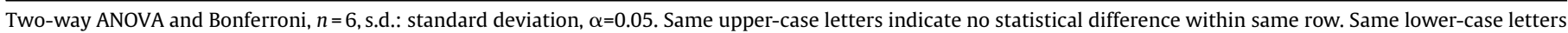
indicate no statistical difference within same column. 


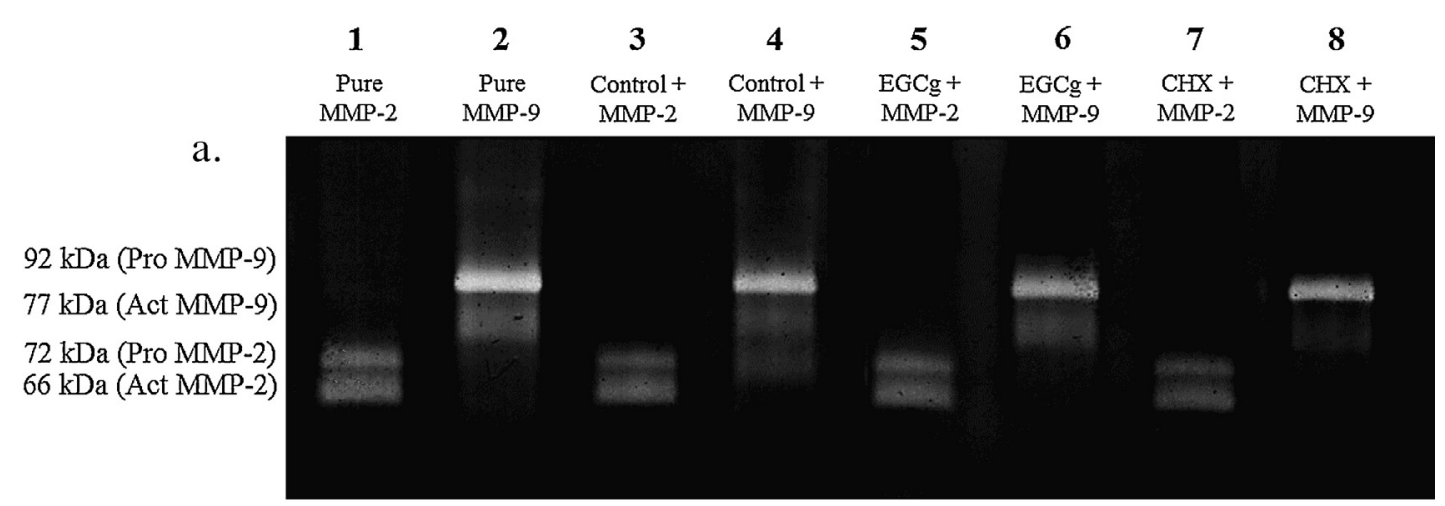

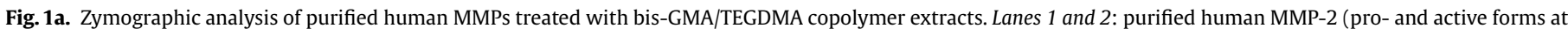

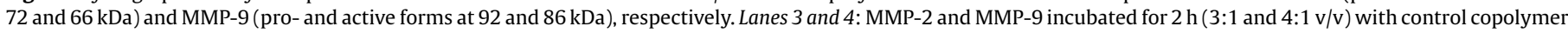

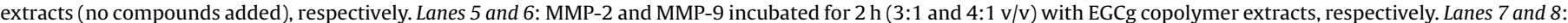

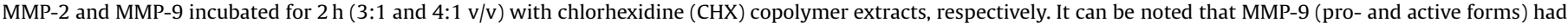
higher inhibition as compared to MMP-2 (pro- and active forms).

fluid flow and cytoplasmic processes of odontoblasts in dentin tubules (Lessa et al., 2010).

Of prospective benefit to the prevention of caries progression, our results confirmed the inhibitory interaction of EGCg and chlorhexidine extracts on gelatinolytic/collagenolytic proteases that can be found in dentin, more specifically to MMP-2 and MMP9. The present results also showed over two-fold inhibition of MMP-9 compared to MMP-2. Similar results were previously reported by Demeule, Brossard, Page, Gingras and Beliveau (2000). In that study, the low $\mathrm{IC}_{50}$ values obtained for EGCg $(1 \mu \mathrm{M})$ with MMP-9 actually suggested that these MMPs could be targets for green tea polyphenols since the EGCg plasma concentration is reported to be $\sim 0.2 \mu \mathrm{M}$ in humans after few cups of tea (Cao \& Cao, 1999; Yang, Liao, Kim, \& Yurkow, 1998). Cao\&Cao Nature 1999 (Demeule 34), Yang et al. Carcinogenesis 1998 (Demeule 35). Not much is known about the molecular mechanisms by which EGCg blocks MMP activities. It has been suggested that inhibition of gelatinases by EGCg may be due to zinc chelation, as polyphenols have high affinity to metal ions (Yang et al., 1998), and zinc is essential for enzymatic activity. Alternatively, Garbisa et al. (Garbisa et al., 2001) suggest a direct EGCg-protein interaction model that is described according to the following three equilibria: I) MMP interacts with EGCg with high affinity constant; II) gelatin interacts with EGCg; III) MMP-EGCg interacts with gelatin leading to the formation of a ternary inactive complex (MMP-EGCg + gelatin $\leftrightarrow$ MMP-EGCg-gelatin). At high EGCg/MMP ratios, gelatinbound enzyme recovery decreases, indicating that the free flavanol competes with the flavanol-MMP complex for binding to gelatin. Since among all green tea catechins ECg (epigallocatechin), followed by EGCg, are shown to be up to $30 \times$ more effective MMP inhibitors than other catechins indicates that the presence of flavanol skeleton with galloyl radical is necessary for producing the inhibitory activity (Demeule et al., 2000).

It has been reported that a chelating mechanism is also involved in the inhibitory mechanism of MMP-2 and MMP-9 by chlorhexidine. This is because the addition of calcium chloride to the assay mixture was shown to prevent the inhibition of these enzymes (Gendron, Grenier, Sorsa, \& Mayrand, 1999). In this present study, compound release rates in $1 \mathrm{~mL}$ deionized water were above the minimum required for EGCg (MMP-2 and MMP-9: 0.00075\%) and chlorhexidine (MMP-2: 0.0001\% and MMP-9: 0.002\%) to inhibit MMPs (Gendron et al., 1999; Yamamoto et al., 2003). However, when comparing our results with previously published results (Gendron et al., 1999; Yamamoto et al., 2003), the main difference noted was that in our study, although with higher compound rates, lower inhibition values were observed. We can only speculate about a possible explanation for our findings. The abovementioned leachable components of bis-GMA/TEGDMA

b.

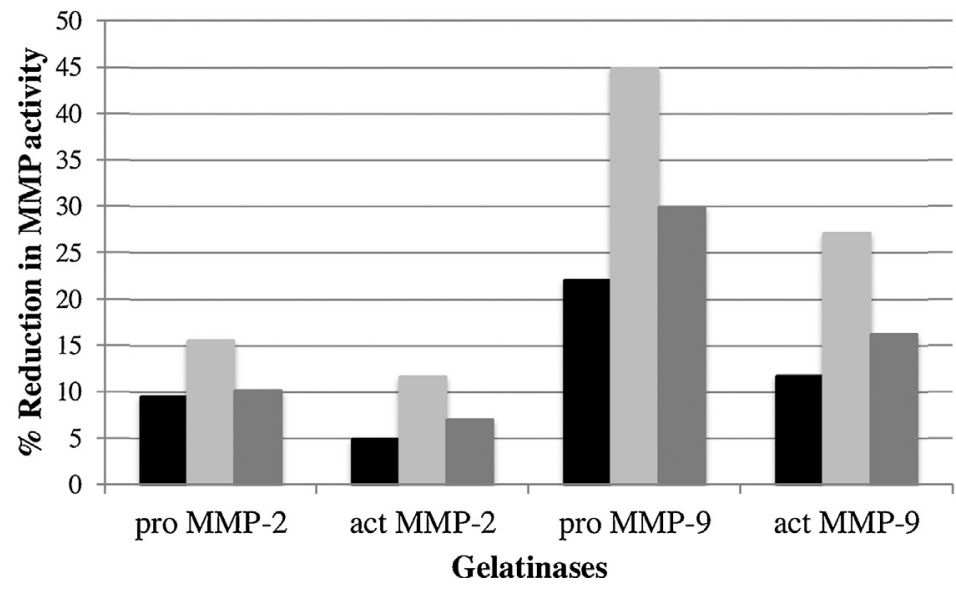

- Control

Chlorhexidine

EGCg

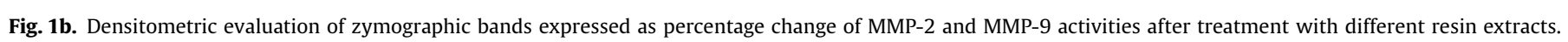


copolymer extract are possibly interacting with EGCg flavanol and dissociated chlorhexidine ions, as well competing for binding with enzymes. The assumption is based on our zymographic results (Figs. 1a and 1b), showing that the control copolymer extract also caused slight but undeniable inhibition to MMP-2 and MMP-9 (pro- and active- forms). Moreover, the interplay between components eluted by the copolymer and consequent availability of active MMP inhibitory species, along with the affinity of EGCg and chlorhexidine for collagenolytic enzymes, might explain EGCg extract to inhibit collagenolytic enzyme activity even at lower concentration than chlorhexidine extract, as shown by the collagenolytic/gelatinolytic enzymatic assay. Indeed, the inhibition of MMP-2 by low concentrations (0.62\%) of pure TEGDMA monomer has been demonstrated (de Carvalho et al., 2011). The molecular mechanisms are believed to rely on complexes formed between metal ions and the monomer crown ethers. Instead, it could also be due to a Lewis acid-base complexation with the monomer carbonyls, or finally, a reaction between the monomer carbonyl moieties with the nucleophilic centers on MMPs outside catalytic domain (de Carvalho et al., 2011).

In experiments testing the inhibition of proteolysis using EnzChek, collagenase from C. histolyticum is used. Even though the collagen degradation sites of bacterial collagenase are different from mammalian enzymes, studies indicate that it can be used as a model in in vitro inhibition experiments related to dental tissues. Chlorhexidine (Kato et al., 2012; Hiraishi et al., 2011; Zheng, Hu, Chen, Zhu, \& Chen, 2012) and EGCg (Kato et al., 2012) have both been shown to inhibit $C$. histolyticum collagenase function in demineralized dentin matrix. Together with the MMP inhibition observed in this study, the EnzChek data support the antiproteolytic activity of chlorhexidine and EGCg extracts. In fact, inhibition by EGCg was seen even for the lowest volume tested, but complete inhibition could not be observed even for the highest volumes. Contrarily, the lowest volume of chlorhexidine did not significantly inhibit the proteolytic activity when compared with control, but the degree of inhibition was much more pronounced for the highest volumes employed and complete inhibition was achieved. In conclusion, the first proposed null hypothesis was accepted as EGCg and chlorhexidine copolymer extracts did not cause significant cytotoxicity on dentin cells when compared to the control extract. Both compounds retained antiproteolytic activity after extraction from a dental copolymer, rejecting the second null hypothesis. In order to improve therapeutic copolymer formulations, further studies are required to determine specific molecular interactions between copolymer leachable components and the incorporated compounds.

\section{Conflict of interest}

The authors declare that there are no conflict of interest involving this article.

\section{Funding}

FAPESP (2011/03618-0) and 2012/03033-4 to B. Zarella. Academy of Finland (256990 PI: L. Tjäderhane), Connaught New Researcher Award (PI: A. Prakki).

\section{Ethical approval}

None.

\section{Acknowledgements}

This study was supported by the following grants: FAPESPBrazil (2011/03618-0 and 2012/03033-4 to B. Zarella); Academy of
Finland (256990 PI: L. Tjäderhane); and Connaught New Researcher Award (PI: A. Prakki).

\section{References}

Anusavice, K. J., Zhang, N. Z., \& Shen, C. (2006). Controlled release of chlorhexidine from UDMA-TEGDMA resin. Journal of Dental Research, 85, 950-954.

Aranha, A. M. F., Giro, E. M. A., Hebling, J., Lessa, F. C. R., \& Costa, C. A. S. (2010). Effects of light-curing time on the cytotoxicity of a restorative composite resin on odontoblast-like cells. Journal of Applied Oral Science, 18, 461-466.

Cao, Y., \& Cao, R. (1999). Angiogenesis inhibited by drinking tea. Nature, 398, 381.

Chen, M. H. (2010). Update on dental nanocomposites. Journal of Dental Research, 89, 549-560.

Delaviz, Y., Finer, Y., \& Santerre, J. P. (2014). Biodegradation of resin composites and adhesives by oral bacteria and saliva: a rationale for new material designs that consider the clinical environment and treatment challenges. Dental Materials, $30,16-32$.

Demeule, M., Brossard, M., Page, M., Gingras, D., \& Beliveau, R. (2000). Matrix metalloproteinase inhibition by green tea catechins. Biochimica et Biophysica Acta, 1478, 51-60.

Garbisa, S., Sartor, L., Biggin, S., Salvato, B., Benelli, R., \& Albini, A. (2001). Tumor gelatinases and invasion inhibited by the green tea flavanol epigallocatechin-3gallate. Cancer, 91, 822-832.

Garcia, M. B., Carrilho, M. R., Nör, J. E., Anauate-Netto, C., Anido-Anido, A., Amore, R. et al. (2009). Chlorhexidine inhibits the proteolytic activity of root and coronal carious dentin. Caries Research, 43, 92-96.

Gendron, R., Grenier, D., Sorsa, T., \& Mayrand, D. (1999). Inhibition of the activities of matrixmetalloproteinases 2, 8, and 9 by chlorhexidine. Clinical and Diagnostic Laboratory Immunology, 6, 437-439.

Hiraishi, N., Yiu, C. K., King, N. M., Tay, F. R., \& Pashley, D. H. (2008). Chlorhexidine release and water sorption characteristics of chlorhexidine-incorporated hydrophobic/hydrophilic resins. Dental Materials, 24, 1391-1399.

Hiraishi, N., Sono, R., Islam, M. S., Otsuki, M., Tagami, J., \& Takatsuka, T. (2011). Effect of hesperidin in vitro on root dentine collagen and demineralization. Journal of Dentistry, 39, 391-396.

Hirasawa, M., Takada, K., \& Otake, S. (2006). Inhibition of acid production in dental plaque bacteria by green tea catechins. Caries Research, 40, 265-270.

Jandt, K. D., \& Sigusch, B. W. (2009). Future perspectives of resin-based dental materials. Dental Materials, 8, 1001-1006.

Kato, M. T., Leite, A. L., Hannas, A. R., Calabria, M. P., Magalhães, A. C., Pereira, J. C., et al. (2012). Impact of protease inhibitors on dentin matrix degradation by collagenase. Journal of Dental Research, 91, 1119-1123.

Kunawarote, S., Nakajima, M., Shida, K., Kitasako, Y., Foxton, R. M., \& Tagami, J. (2010). Effetc of dentin pretreatment with mild acidic $\mathrm{HOCl}$ solution on microtensile bond strength and surface pH. Journal of Dentistry, 38, 261-268.

Lessa, F. C., Nogueira, I., Huck, C., Hebling, J., \& Costa, C. A. (2010). Transdentinal cytotoxicity effects of different concentrations of chlorhexidine gel applied on acid-conditioned dentin substrate. Journal of Biomedical Materials Research Part B Applied Biomaterials, 92, 40-47.

Leung, D., Spratt, D. A., Pratten, J., Gulabivala, K., Mordan, N. J., \& Young, A. M. (2005) Chlorhexidine releasing methacrylate dental composite materials. Biomaterials 26, 7145-7153.

Mäkelä, M., Salo, T., Uitto, V. J., \& Larjava, H. (1994). Matrix metalloproteinases (MMP-2 and MMP-9) of the oral cavity: cellular origin and relationship to periodontal status. Journal of Dental Research, 73, 1397-1406.

Mankovskaia, A., Levesque, C. M., \& Prakki, A. (2013). Catechin-incorporated dental copolymers inhibit growth of Streptococcus mutans. Journal of Applied Oral Science, 21, 203-207.

Mazzoni, A., Mannello, F., Tay, F. R., Tonti, G. A., Papa, S., Mazzotti, G., et al. (2007). Zymographic analysis and characterization of MMP-2 and -9 forms in human sound dentin. Journal of Dental Research, 86, 436-440.

Pallan, S., Furtado Araujo, M. V., Cilli, R., \& Prakki, A. (2012). Mechanical properties and characteristics of developmental copolymers incorporating catechin or chlorhexidine. Dental Materials, 28, 687-694.

Rasines Alcaraz, M. G., Veitz-Keenan, A., Sahrmann, P., Schmidlin, P. R., Davis, D., \& Iheozor-Ejiofor, Z. (2014). Direct composite resin fillings versus amalgam fillings for permanent or adult posterior teeth. Cochrane Database Systematic Reviews, 31, CD00562.

Roy, M., Chakrabarty, S., Sinha, D., Bhattacharky, R. K., \& Siddiqi, M. (2003) Anticlastogenic, antigenotoxic and apoptotic activity of epigallocatechingallate: green tea polyphenol. Mutation Research, 524, 33-41.

Santiago, S. L., Osorio, R., Neri, J. R., Carvalho, R. M., \& Toledano, M. (2013). Effect of the flavonoid epigallocatechin-3-gallate on resin-dentin bond strength. Journal of Adhesive Dentistry, 15, 535-540.

Shin, M. S., Yeon, K. Y., Oh, S. B., \& Kim, J. S. (2006). Expression of TRP channels in mouse dental papilla cell-23 (MDPC-23) cell line. International Journal of Oral Biology, 31, 135-140.

Tjäderhane, L., Nascimento, F. D., Breschi, L., Mazzoni, A., Tersariol, I. L., Geraldeli, S. et al. (2013). Strategies to prevent hydrolytic degradation of the hybrid layer-a review. Dental Materials, 29, 999-1011.

Tjaderhane, L., Larjava, H., Sorsa, T., Uitto, V. J., Larmas, M., \& Salo, T. (1998). The activation and function of host matrix metalloproteinases in dentin matrix breakdown in caries lesions. Journal of Dental Research, 77, 1622-1629. 
Van Rijkom, H. M., Truin, G. J., \& vant Hof, M. A. (1996). A meta-analysis of clinical studies on the caries-inhibiting effect of chlorhexidine treatment. Journal of Dental Research, 75, 790-795.

Vidal, C. M. P., Tjäderhane, L., Scaffa, P. M., Tersariol, I. L., Pashley, D., Nader, H. B., et al. (2014). Abundance of MMPs and cysteine cathepsins in caries affected dentin. Journal of Dental Research, 93, 269-274.

Xu, X., Zhou, X. D., \& Wu, C. D. (2012). Tea catechin Epigallocatechin gallate inhibits Streptococcus mutans biofilm formation by suppressing gft genes. Archives of Oral Biology, 57, 678-683.

Yamamoto, M. M., Suzuki, N., Sawai, Y., Miyase, T., Sano, M., Ohta, A. H., et al. (2003). Association of suppression of extracellular signal-regulated kinase phosphorylation by epigallocatechin gallate with the reduction of matrix metalloproteinase activities in human fibrosarcoma HT1080 cells. Journal of Agriculture and Food Chemistry, 51, 1858-1863.
Yang, G. Y., Liao, J., Kim, K., \& Yurkow, E. T. (1998). Inhibition of growth and induction of apoptosis in human cancer cell lines by tea polyphenols. Carcinogenesis, 19(4), 611-616.

Yasuda, Y., Inuyama, H., Maeda, H., Akamine, A., Nor, J. E., \& Saito, T. (2008). Cytotoxicity of one-step dentin bonding agents toward dental pulp and odontoblast-like cells. Journal of Oral Rehabilitation, 35, 940-946.

Zheng, X., Hu, J., Chen, Y., Zhu, Y., \& Chen, H. (2012). AFM study of the effects of collagenase and its inhibitors on dentine collagen fibrils. Journal of Dentistry, 40 $163-171$.

de Carvalho, R. V., Ogliari, F. A., Marques, M. R., de Souza, A. P., Petzhold, C. L., Line, S, R. P., et al. (2011). Inhibition of the activity of matrix metalloproteinases 2 by triethylene glycol dimethacrylate. Clinical Oral Investigation, 15, 643-648.

de Souza, L. B., de Aquino, S. G., de Souza, P. P., Hebling, J., \& Costa, C. A. (2007). Cytotoxic effects of different concentrations of chlorhexidine. American Journal of Dentistry, 20, 400-406. 